\title{
Russian Borrowings in the Aleutian and Den'aina Languages: Causes and Assimilation
}

\author{
Sheina I.M. \\ Department of Oriental Languages and Teaching \\ Methodology \\ S.A. Esenin State University \\ Ryazan, Russia \\ i.sheina@365.rsu.edu.ru
}

\author{
Sidorina E.I. \\ Department of Oriental Languages and Teaching \\ Methodology \\ S.A. Esenin State University \\ Ryazan, Russia
}

\begin{abstract}
The article aims to identify the correlation between the reasons for borrowing Russian words into the indigenous peoples' languages and semantic assimilation of the loan words from the perspective of their interaction with native lexical units. Russian borrowings are viewed as a part of Russian historical and cultural heritage of Russian America. Commonalities in the systemic impact of the Russian language on the Aleutian and Dena'ina languages, such as similar causes of borrowings, similarities in the distribution of loan words in the thematic groups, common tendencies in the process of adaptation show that there were numerous common features in the cross-cultural and cross-language contacts.
\end{abstract}

Keywords-Russian America; borrowing; causes; the Aleut language; Dena'ina; semantic assimilation

\section{INTRODUCTION}

The historical and cultural heritage of Russian America is multifaceted, and though interrelationships between the Russian colonists and the indigenous peoples were not always peaceful, changes in the worldview of the Aleuts and the Den'aina people prove that numerous objects, phenomena, ideas and concepts became a part of their experience thanks to intercultural contacts with Russians. These changes can be revealed through linguistic analysis of Russian borrowings, which in the context of cross-language interference manifest the patterns of cross-language interaction and cross-cultural contacts.

Russian colonists in Alaska transformed the material and spiritual culture of the indigenous people to a great degree, opening new opportunities, implementing new patterns of interpersonal relationships, new economic and social activities.

The comparative analysis of Russian borrowings in the Aleut and Den'aina languages, which adopted the largest number of Russian words, enables us to treat the impact produced by the Russian conceptual and linguistic pictures of the world as an important aspect of the historical and cultural heritage of Russian America.

The goal of this research is to identify correlation between causes of borrowings, their semantic assimilation and the

Research is done with support of the Russian Scientific Foundation (Agreement № 17-18-01567 dated by May 19, 2017). nature of cross-cultural interaction between Russians and the indigenous peoples of Alaska.

\section{LITERATURE REVIEW}

Authors describing the historical and cultural heritage of Russian America argue that the results of cross-cultural contacts of the Russian colonists and the Alaska population reveal themselves in many aspects: in daily routine, in family life, in social and economic relations, in fishery and hunting, in the sphere of entertainment and in their religious picture of the world with adoption of new Christian values $[1 ; 2 ; 3 ; 4]$.

A unique consequence of close contacts is the so-called Ninilchik Russian, an Alaskan variant of the Russian language still existing in some parts of Alaska, which was thoroughly studied by M. B. Bergelson and A. A. Kibrik [5]. Treating this phenomenon as «a precious artifact» [5: 39], the authors created a systemic description of its phonetics, lexicon and grammar and compiled its dictionary contributing greatly to the studies of Russian America heritage.

Language contacts, language interference and borrowings have been in the focus of scholars' attention for several decades. Linguists have examined the causes, ways and sources of borrowings, the role of culture in these processes and adaptation of foreign language units in the recipient languages. This research is based on the works of E. Haugen, L.P. Krysin, U. Weinreich and other scholars $[6 ; 7 ; 8]$.

The Aleutian language as it is spoken by the Aleuts of the Commander Islands has been thoroughly studied by Russian linguists [9; 10]. Another source of data is K. Bergsland's «Aleut Dictionary» with a list of Russian loan words [11]. Russian borrowings in the Dena'ina language were singled out in D. Kari's «Dena'ina Topical Dictionary» and «Dena'ina Stem/Morpheme Dene Dictionary»[12;13].

\section{RESEARCH METHODOLOGY}

The baseline of this research consists in viewing lexical borrowings as a tool to manifest the nature and results of cross-cultural interaction between Russian colonists and the indigenous peoples. E. Sapir defined the lexicon of a language «as a complex inventory of all the ideas, interests and occupations that take up the attention of the community» [14: 49]. If a language provides a word for an object or activity, 
that object or event becomes culturally significant. Accordingly, if a language adopts a new lexical item, it signals changes in the people's experience, attitudes, perception, which constitute their shared worldview.

Penetration into the causes of borrowings, their thematic organization and semantic adaptation gives us an insight into the evolution of the indigenous peoples' mentality under the influence of Russian world view and culture.

To achieve the goals of the research we applied the following methods.

The continuous sampling method helped to make lists of Russian borrowings in the Aleutian and Den'aina languages.

Analysis of dictionary entries and the componential analysis revealed the scope of meaning of the adopted lexical units, semantic shifts, which occurred in the process of assimilation, in comparison with synonymous native words.

Analysis of thematic groups in combination with the statistical analysis enabled us to single out the essential thematic groups and their quantitative characteristics.

Analysis of cognate words clusters gives the opportunity to identify the inner form of the native word and make distinctions among synonyms.

Studying the influence exercised by Russian culture and world view on the way of life and spiritual values of the indigenous peoples will give us a more profound understanding of Russia's role in cultural and historical experiences of other countries.

The results obtained in this research can be used to develop the theory of borrowings from the perspective of intercultural communication. From this perspective we can better understand how borrowed words fill in the gaps in the recipient language to promote interaction with the donor culture.

Revealing the features of the systemic impact produced by the Russian language on the indigenous peoples' languages gives insight into the regularities which govern the process of the interaction of world views.

Studying Russian borrowings in the indigenous peoples' language from the perspective of Russian historical and cultural heritage and the results of this research paves the way to shaping the historical consciousness of the younger generation. Historical and linguistic education should include studies of the role of Russia and the Russian language in the North Pacific Region.

\section{RESULTS}

T.P. Golovatskaya defines lexical borrowings as all kinds of innovations in the lexical system of language which have become its part owing to contacts with other languages [15: 7]. The recipient language can adopt not only words in their form and meaning, but the source language exercises an influence on its lexical and semantic systems via calques, semantic borrowings, mixed borrowings, etc. As this research is focused on changes in the indigenous peoples' world view, it is critical to examine lexical borrowings proper objectifying crosscultural contacts in the most conspicuous way.

Borrowings from other languages, or loan words, are a result of cross-cultural and cross-linguistic contacts. They can be adopted together with new objects and phenomena, but they can also be a consequence of changes in the world view of the borrowing language community.

External causes of borrowings are usually obvious as they are related to social and economic changes brought about by cross-cultural contacts. Analyzing the great influx of Russian words denoting objects of everyday use (tools, kitchen utensils, furniture, etc.) into the Aleutian and Dena'ina languages we link it with the fact that Russian colonists introduced those objects into everyday life of the Aleuts and Dena'ina. Statistical analysis shows that the largest number of borrowed Russian words in both languages belong to the thematic groups «Clothing», «Food, Cooking and Eating Utensils», «Tools, Hunting and Fishing Devices», «Household furnishings and personal belongings», «Houses and Shelters», «People», «Religious Terms» (see Table I). Identifying thematic groups we follow J. Kari's «Dena'ina Topical Dictionary» [12]

Religious terms form a separate group, as they were a result of the Russian missionaries work translating the Holy Script. Table I shows only borrowings proper, when both the form and the meaning of the word is borrowed, whereas translators of the Bible used many translation loans, when each component of a compound word or a phrase was translated into the recipient language and semantic borrowings when a native word acquired a foreign meaning.

A considerable number of borrowed words coincide in two languages, as is also shown in Table I.

Both languages borrowed the same professional words (brodni - rubber boots for fishing), dialectal words (ganza smoking pipe, the Siberian dialect) and words which are now archaisms and historical words (kichka - female headgear, sertuk - jacket).

Similar tendencies were found in the process of semantic assimilation of Russian loanwords: the prevailing mechanism is metonymy, i.e. transference from one referent into another is based on contiguity, and the scope of meaning is narrowed in the majority of cases.

Linguistic causes of borrowing are often connected with the necessity to fill the gaps in the linguistic classifications offered by the native language. We call this factor «the need for more detailed specification of a particular area of experience». Thus, the Aleuts and the Dena'ina divided a year into seasons, but their division reflected their traditional way of life closely connected with the climate. For example, in the Aleutian language «chagalix» means «the month of seal young» and it corresponds to the period from July to September in the European calendar. In the Dena'ina language the month which more or less corresponds to April was called «goose month» - «nut'aq'i'n'u». Russian colonists introduced changes into the traditional schedule of the indigenous peoples and the new patterns of life required new names for months.

Contacts with Russians enriched the lexicon of the recipient languages with words that were synonymous to native words and added to the synonymic sets. The borrowings underwent the process of adaptation in interaction with the native lexical units. The Aleutian language had had several native words denoting a person working with wood: «aniigna-X», «sugana-X», «hyaagalimagna-X», «awana-X» before it borrowed the Russian word «master» assigning to it the narrower meaning «carpenter». 
borrowing, being derived from the borrowed Russian word «axe» (topor - «tukuulu-X») with the help of a native suffix.

It is worth noting that the Russian word «master» was also borrowed into the Dena'ina language with the same semantic shift, adding to the synonymic set of native words «luqeldenen» - «one who is handy», and «chik'a ghe ghetnu'en»- «one who works on wood».

Thus, on one hand, expansion of this synonymic set can be explained by the law of radiation of synonyms (master), which means the tendency among synonyms to acquire a new semantic feature if one of them has got it. On the other hand, new synonyms served to meet the need for further differentiation of this professional sphere (tukuuluda-x). In both cases we deal with metonymy and specification of meaning.

Russian words penetrated even in the sphere of kinship terms, which is a rare case, as kinship terms is a very rigid lexical semantic group, which objectifies the people's view of family relations. The Aleutian and the Dena'ina languages had separate terms for elder brother and younger brother, a man's brother and a woman's brother. Both peoples evidently got aware of a certain lacuna when they borrowed the Russian word "brat" with an embracing meaning.

Some semantic shifts in the meanings of borrowed words can evidently be explained by the context in which they were used by Russian colonists. Let' regard the following examples.

The Russian word «trap», a borrowing from Dutch with the meaning «ladder, ramp», acquired one more meaning in the Aleutian language - «stairs, staircase». The native word «analux» with this meaning - «ladder-pole to the exit hole in the roof of the ancient sod house» was derived from the verb «ane», which means «to go out», with the help of the suffix «alux», which means «place». The native word with clear motivation acquired a foreign synonym evidently owing to the associations which the ladder to a native sod house caused in the minds of Russians. A sod houses, or a barabara, is semisubterranian, and the ladder which led from a low door to the room located underground looked very much like a ramp.

The Russian word «mal'chishka», according to T.F. Efremova's Explanatory Dictionary of the Russian Language, has the negative connotative feature - «a shade of disdain» as one of its semantic components among others, such as «young, immature» $[16,17]$. In the Dena'ina language it means «boy who is mischievous», which shows a shift of the focus to a more negative judgment. This shift can be explained by often use of the Russian word by Russians with this strengthened negative connotation.

The word «shirt» in the Dena'ina language - «galenga» was adopted from the Russian language, only it has nothing to do with the Russian word «rubashka». "Galenga» is the assimilated Russian word «gollandka» - a uniform shirt of Russian seamen. We can make the assumption that Russians often replaced the more general words by the more specific one and the natives adopted it with a widened meaning.

These examples illustrate the idea that semantic shifts that occurred in the process of assimilation were caused by the contextual use of the Russian words.

\section{CONCLUSIONS}

Analysis of Russian borrowings in the Aleutian and Dena'ina languages reveals commonalities in the nature of

\footnotetext{
${ }^{1}$ Shortenings: al. - Aleutian, den. - Dena'ina
} 
[5] M. Bergelson, A. Kibrik, "The Russian language in the cook inlet area:

cross-cultural and cross-language contacts between Russian colonists and the indigenous peoples.

External causes of borrowings brought a large number of words denoting new objects and phenomena. Coincidences in the thematic groups show that influence on material culture on the part of Russian colonists was similar.

Linguistic cause of borrowings account for loan words that helped elaborate linguistic classifications of certain areas of experience, organize them in the way that manifested changes in the indigenous peoples' world view.

One of the reasons for semantic shifts in the process of adaptation of Russian loan words was meaning variation in their contextual use.

Commonalities in the systemic impact of the Russian language on the Aleutian and Dena'ina languages, such as similar causes of borrowings, similarities in the distribution of loan words in the thematic groups, common tendencies in the process of adaptation show that there were numerous common features in the cross-cultural and cross-language contacts.

\section{DISCUSSION}

Cross-cultural and cross-linguistic contacts between ethnic groups often result not only in adoption of new objects and borrowing of words but sometimes in profound changes in world view.

The language contact situation in Alaska was unique. Numerous Russian loan words caused rearrangement in the systemic relations within the lexicon of each native language.

From this perspective Russian borrowings in the indigenous peoples' languages can give us data on how new concepts were integrated into these peoples' world view under the influence of Russian culture and the Russian language.

The conceptual approach will be effective for the analysis of religious words adopted with Orthodox Christianity. Translation of the Holy Scripture into the indigenous languages was not easy, because use of too many foreign words could make the text difficult for understanding. Translation loans and semantic borrowings used by the Russian priests deserve special attention as the choice of native elements in creation of a new concept was inevitably connected with their native meanings.

The lexicon of any language is the most accurate mirror of a community's ideas about the world, their values and attitudes. Further studies of Russian borrowings in the Alaskan languages will give an opportunity to devise a linguistic map of the Russian historic and cultural heritage in Alaska in its diverse aspects.

\section{References}

[1] A.Yu. Petrov, "Histoty and heritage of Russian America: problems, directions, prospects of research", New and recent history, Moscow. 2016, vol. 5. pp. 177-182.

[2] A.Yu. Petrov, "Succession of Alaska: discussion issues of the RussianAmerican deal of 150 years ago", The New Historical Bulletin, Moscow. 2017, vol. 2 (52). pp. 105-115.

[3] A.V. Grinev, "The nature of the relationship of Russian colonialists and Alaska natives", History questions, Moscow. 2003, vol. 8. pp. 96-111.

[4] M.V. Shilovskiy, "Why did Russia sell Russian America? (on the 150th anniversary of the signing of the treaty (March, 18 (30), 1867) on the cession of the north American colonies to the United States", Bulletin of the Tomsk State University. History, Tomsk. 2017, vol. 50. pp. 24-30. University Journal of Philology, Tomsk. 2018, vol. 54. pp. 29-41.

[6] L.P. Krysin, "The Russian Word: Native and Foreign. Studies on the Modern Russian language and Sociolinguistics", Languages of Slavic Culture Publishers, Moscow. 2004, 888.

[7] U. Weinreich, "Languages in Contact: Problems and Findings", High School Pub., Kiev. 1979, pp. 25-60.

[8] E. Haugen, "The Process of Borrowing", New in Linguistics, Progress Publishers, Moscow. 1972, vol. 6, pp. 344-382.

[9] E.V. Golovko, N.B. Vakhtin, A.S. Asinosky, "The Aleut Language of the Commander Island: Bering Aleut", Nauka Publishers, St. Petersburg. 2009, 355.

[10] E.V. Golovko, "Spatial orientation system in the Aleut language", Bulletin of St. Petersburg University, Series 9. Language and Literature, St. Petersburg. 2015, vol. 3, pp. 25-35.

[11] K. Bergsland, Aleut Dictionary, Alaska Native Language Center, University of Alaska, Fairbanks. 1994, 755.

[12] J, Kari, Dena'ina Topical Dictionary, Alaska Native Language Center, University of Alaska, Fairbanks. 2013, 370.

[13] J, Kari, Dena'ina Stem/Morpheme Dene Dictionary, Dena'inaq' Titaztunt \& Alaska Native Language Center. 2018, 53.

[14] E. Sapir, Language an Introduction to the Study of Speech, Book Jungle Publishers, English, 2008, 224.

[15] T.P. Golovatskaya, "Classification of Russian Borrowings in Eskimo Textbooks and Fiction", Herzen University Journal of Humanities \& Science, St. Petersburg. 2008, vol. 38(82), pp.127-131.

[16] Alexsandr S. Kuznetsov. Russian Professor's meeting. Russian Journal of Physical Education and Sport. 2019, 14(1), pp. 17-22. DOI: 10.14526/2070-4798-2019-14-1-18-24

[17] T.F. Yefremova, New Dictionary of the Russian Language: in 2 vol., Russian Language publishers, Moscow. 1209 p. 